\title{
Effect of the Training of Nurses on the Reduction of Noise Pollution in
} Intensive Care Units

\author{
Zahra Godarzi ${ }^{1}$, *Fatemeh Oskouie ${ }^{2,3}$, Kamal Azam ${ }^{4}$, Mohammad Monazzam $^{5}$, Tahere Loni ${ }^{6}$ \\ Jaleh Ghasemi $^{7}$, Masoud Ahmadpoor ${ }^{8}$
}

\begin{abstract}
Background \& Aims: Noise pollution is becoming a severe issue for the patients admitted in intensive care units (ICUs). For the reduction of noise pollution in hospitals, researchers recommend proper training and adherence to protocols. The present study aimed to assess the effect of the training of nurses on the reduction of noise pollution in ICUs.

Materials \& Methods: This clinical trial was conducted at Tehran University of Medical Sciences and Iran University of Medical Sciences, which were randomly selected as the intervention and control groups, respectively. Before the intervention, noise intensity was measured at four locations inside the ICUs of the selected universities (entrance and exit, nursing stations, center of the department, and patients' bedside). Afterwards, methods for the control of noise pollution were introduced to the nurses in the intervention group in the form of a training workshop. Two months after the intervention, noise intensity was measured in the selected locations in the intervention and control groups. Noise intensity was measured using a sound meter in decibels $(\mathrm{dB})$, and the $\mathrm{dB}$-scale sound pressure level in LA networks (corresponding to the hearing of humans) was measured every two hours for three consecutive days.

Results: According to the results of paired t-test, the intra-group effects of training regarding the correlation of the mean and standard deviation of the sound pressure level was estimated at $55.37 \pm 5.43$ and $57.79 \pm 4.96$ in the intervention group before and after the intervention, respectively, which indicated a significant difference in this regard $(\mathrm{P}<0.001)$. In addition, comparison of the intervention and control groups using independent t-test indicated a significant difference between the groups before and after the intervention $(\mathrm{P}<0.001)$. Also, the result of covariance test was not significant in intervention group and control group.

Conclusion: According to the results, the training of nurses on the control of noise pollution was effective in the reduction of this issue. Therefore, it is recommended that noise pollution in hospitals be reduced through implementing in-service training workshops for nurses, asking nurses to be quite and promote sleep, and exploit silence signs in ICUs.
\end{abstract}

Keywords: Education, Nurse, Noise Pullotion, Intensive Care Unit

\section{Conflict of Interest: No}

How to Cite: Godarzi Z, Oskouie F, Azam K, Monazzam M, Loni T, Ghasemi J, Ahmadpoor M. Effect of the Training of Nurses on the Reduction of Noise Pollution in Intensive Care Units. Iran Journal of Nursing. 2019; 31(116):75-85.

Received: 22 Nov 2018

Accepted: 21 Feb 2019

\footnotetext{
1. Lecturer, Department of Pediatrics and Neonatal Intensive Care, School of Nursing and Midwifery, Tehran University of Medical Sciences, Tehran, Iran

2. Professor, Nursing Care Research Center, Iran University of Medical Sciences, Tehran, Iran (*Corresponding author) Tel: 021-88671613 Email: oskouie.f@iums.ac.ir

${ }^{3}$. Professor, Department of Community Health Nursing, School of Nursing and Midwifery, Iran University of Medical Sciences, Tehran, Iran

4. Professor, Department of Occupational Health, School of Health, Tehran University of Medical Sciences, Tehran, Iran

5 . Professor, Department of Occupational Health, School of Health, Tehran University of Medical Sciences, Tehran, Iran

${ }^{6}$. Head Nurse, Neonatal Intensive Care Unit, Hazrat Rassoul Hospital, Iran University of Medical Sciences, Tehran, Iran

7. Head Nurse, Emergency Pediatric Intensive Care Unit, Children's Medical Center, Tehran University of Medical Sciences, Tehran, Iran

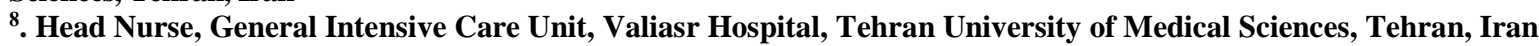




\title{
تأثير آموزش برستاران بر كاهش آلودىى صوتى در بخشهاى مراقبت ويثه
}

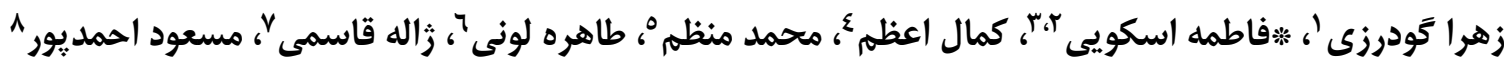

\begin{abstract}
جكيده

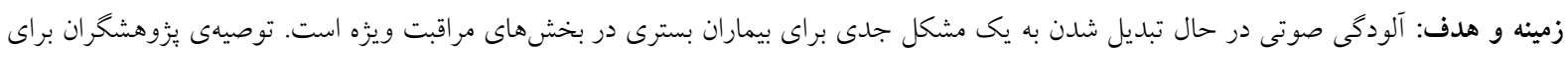

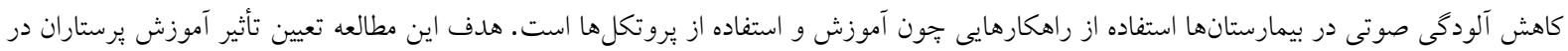

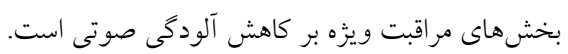

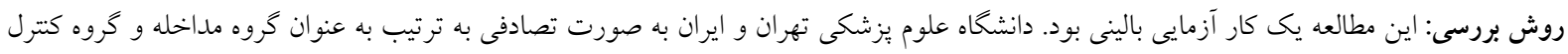

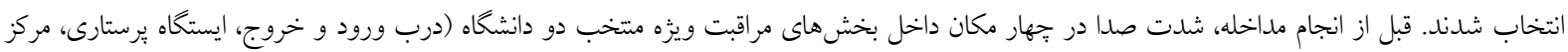

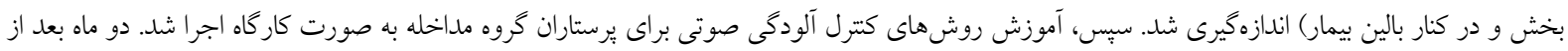

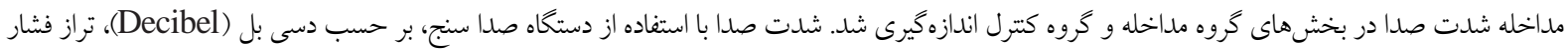

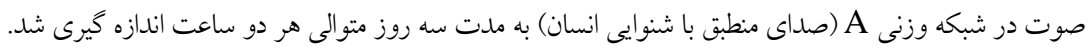

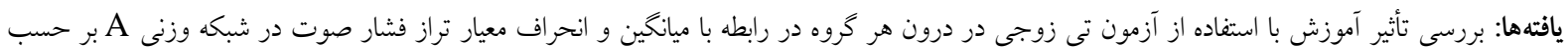

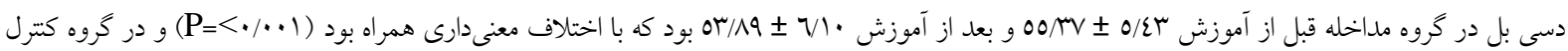

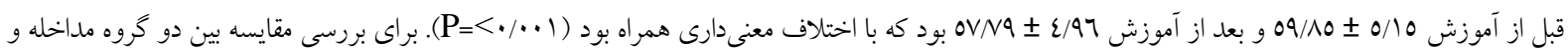

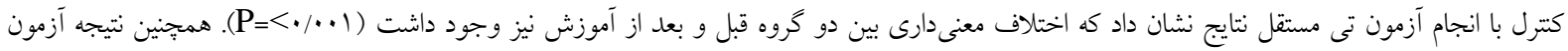

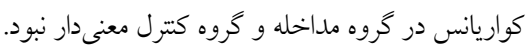

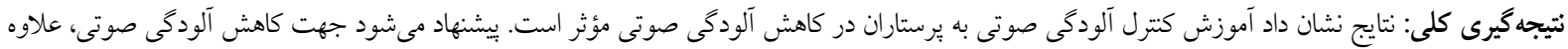

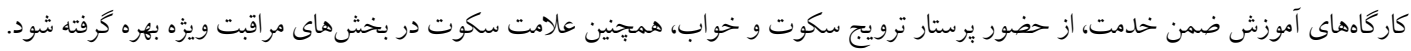

كليد وازهها: آموزش، برستار، آلودگى صوتى، بخش مراقبت ويزٔه

\author{
تعارض منافع: ندارد

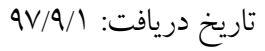 \\ تاريخ بذيرش:
}

شماره تماس:

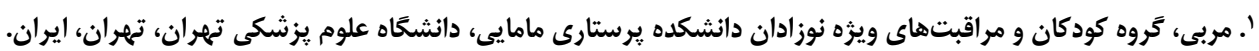

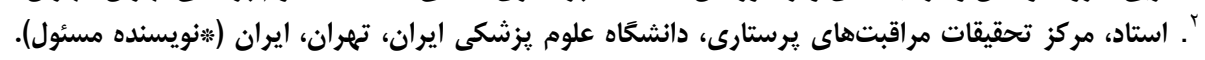
Email: oskouie.f@iums.ac.ir

+r)-117TVITIr

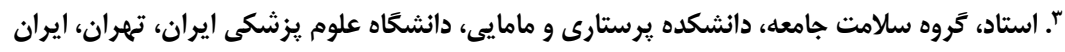

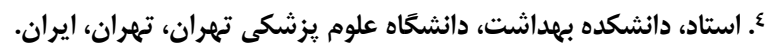

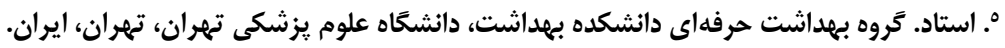

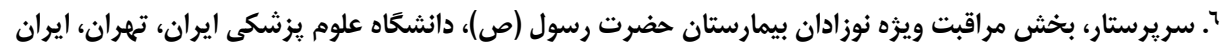

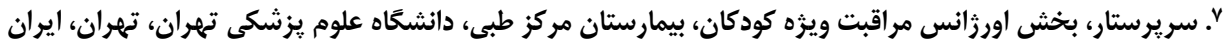

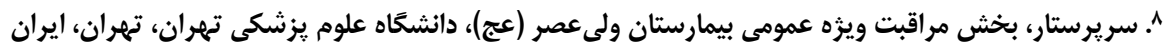


عامل تغيير خلقى - ذهنى بوده است (17). بيشترين آزار

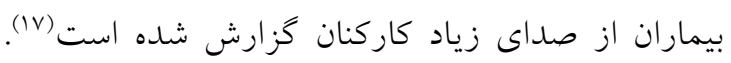
به طور معمول بسترى شدن بيمار در بيمارستان رئان

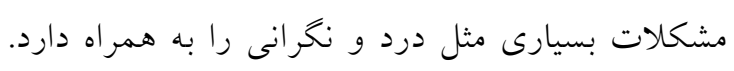

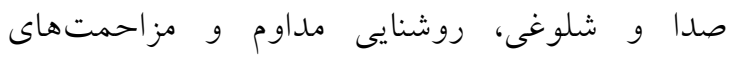
مراقبين (مثل كارهاى برستاران و درمانخرهاى تنفسى روسيى)

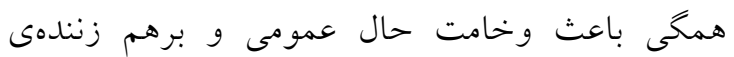

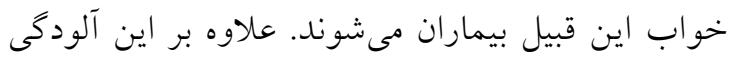

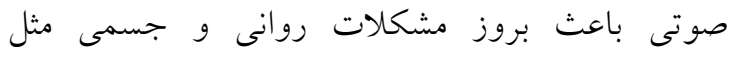
بهبودى ديررس و افزايش فشارخون و ضربان قلب هم

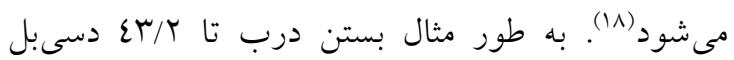

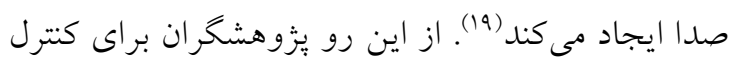

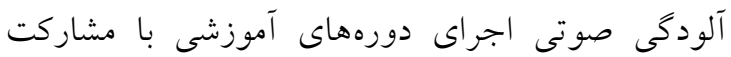

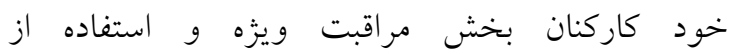

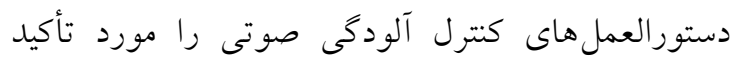
قرار مى دهند (r.r. (r). بر اساس دستوالعمل سازمان بهداثت جهانى "تحت عنوان

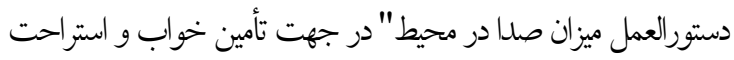

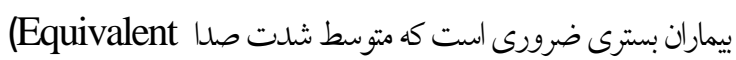
continuous A-weighted sound pressure Level ناشى از صداى تجهيزات محيط ييمارستان و (LAeq/dBA leq)

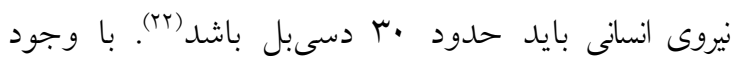

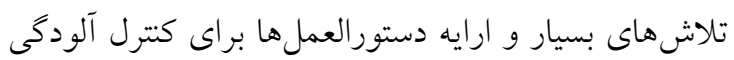
صوتى در بيمارستانها و به خصوص بخش مراقبتهاى

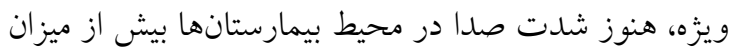
توصيه شده توسط سازمان بهداشت جهانى است (بآ, ع). صداى يرستاران و مكالمهى آنان جزء جدايى نايذير و و علت اصلى صدا و آلودگى صوتى محيط بيمارستان است

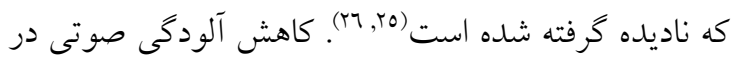

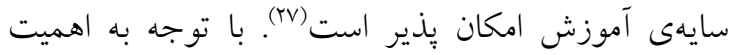

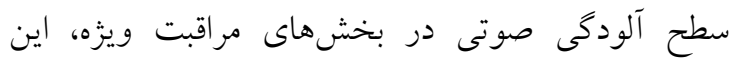
مطالعه با هدف تعيين تأثير آموزش يرستاران بر كنترل

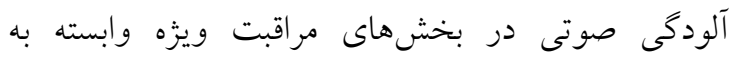

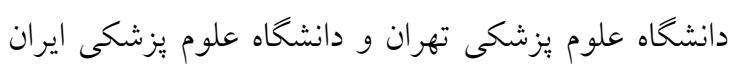

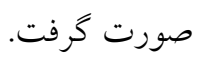
صدا (sound) يك درى حسى است، اما وقتى كه الكوهاى يِيجيدهاى از امواج صوتى، موسيقى و كفتار

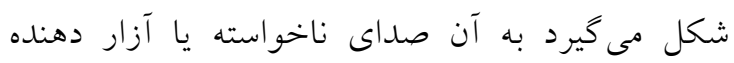

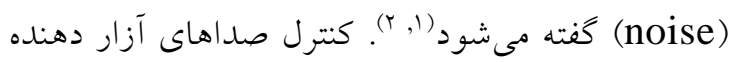

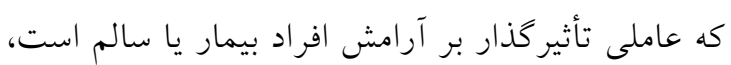

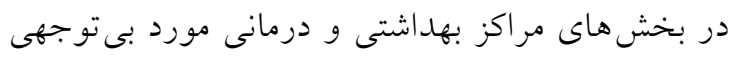

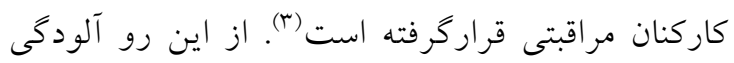
صوتى در حال تبديل شدن به يك مشكل جدى به

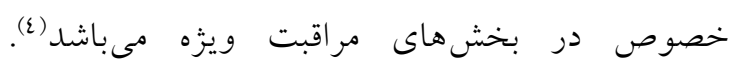

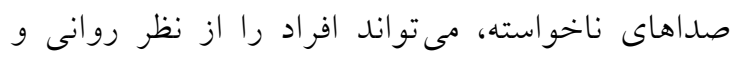

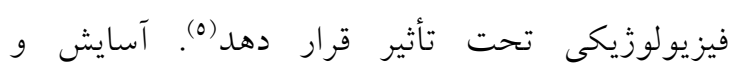
بهبودى بيماران تحت تأثير كيفيت خواب آنان است (1). كمبود خواب در بخش مراقبت ويزه به دليل شرايط

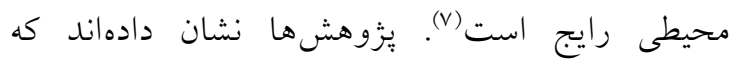

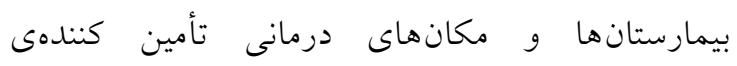

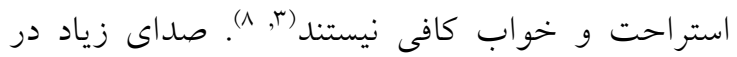
تمام بخشهاى بيمارستانى از ديرباز وجود داشته ليته

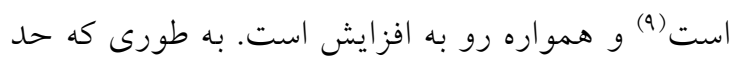

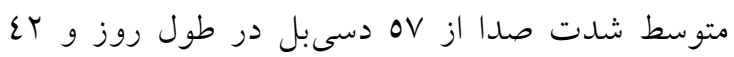

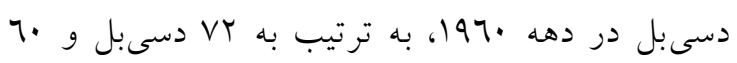

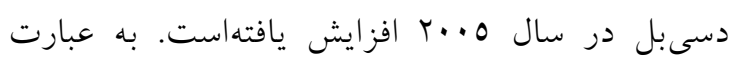

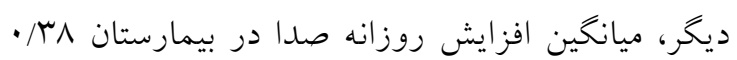

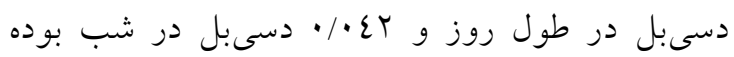

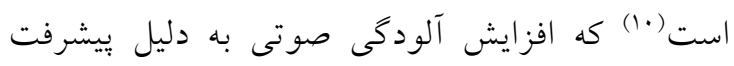

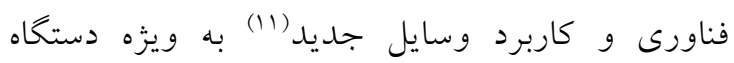

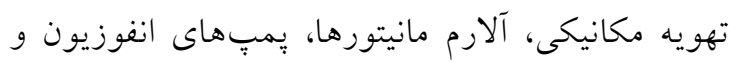

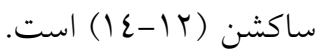
نتايج يزوهش هاى كذشته مربوط به بخش رهاى مراقبت

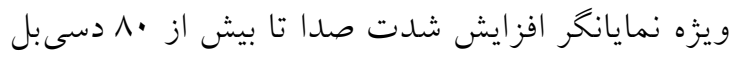
است در حالى كه متوسط شدت صدا 0ع دسىبل در

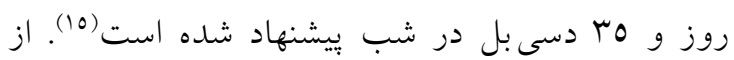
طرفى نتايج مطالعه در مورد وقوع سندروم بخش مراقبت ويزه، نشانكر محروميت شديد خواب به عنوان 
شد. عددى كه دستخاه صداسنح در آن لحظه نشان مىداد

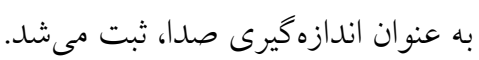
تراز فشار صوت نياز به يك ارزش عددى واحد دارد؛

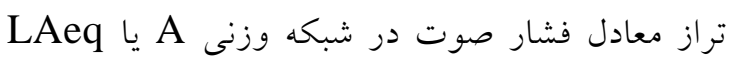
Equivalent continuous A-weighted sound ) C-) LC يا C و شبكه وزنى (pressure Level) (weighted sound pressure Level اندازمخيرى صدا را منطبق بر سيستم شنوايى انسان را نشان مى دهند.

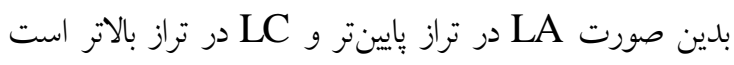

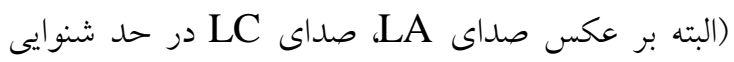

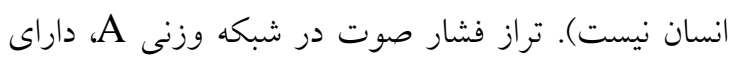
وزنى است كه تا به فركانس حساسيت سيستم شنوايى صني انسان برسد، مقياس اين تراز صدا جهت ارزيابى مشكلات آلودخى صوتى در محيط كاربرد دارد، به طورى كه در آناليز

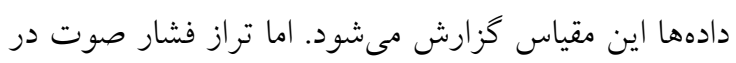
شبكه وزنى C طيف وسيعى از كستره فركانس ولى قابل

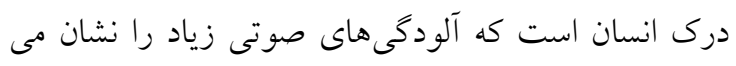

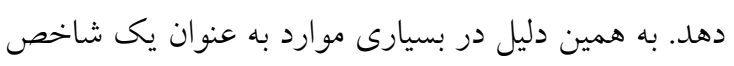

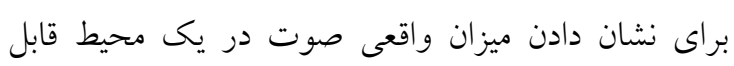

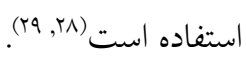
جهت جمع آورى صدا از استاندارد اندازهيرى صدا در استور

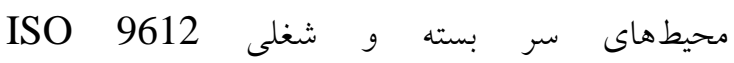
International Organization for ) (Standardization آلودكى صوتى در بخشهاى مورد مطالعه تبعيت شد (r).)

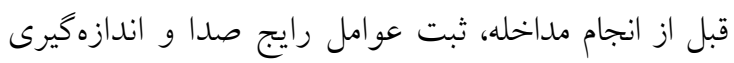

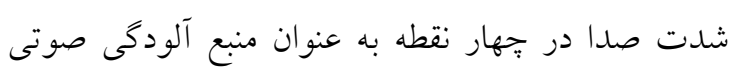

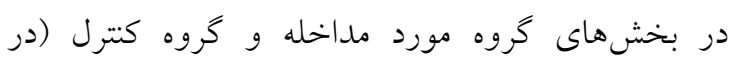
قسمت درب ورود و خروج، در محوطه ايستگاه

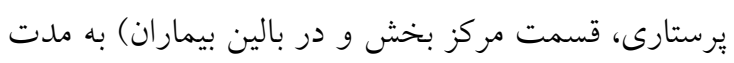

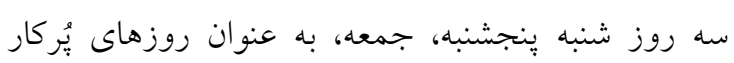

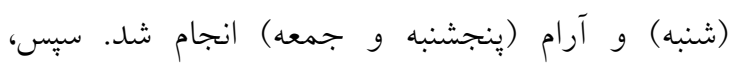
آموزش روشهاى كترل آلودخى صوتى براى برستاران گروه

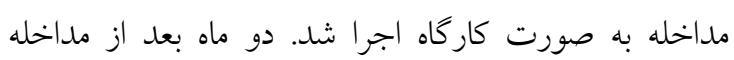

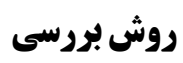

مطالعه حاضر به روش كارآزمايى بالينى همراه با كروه

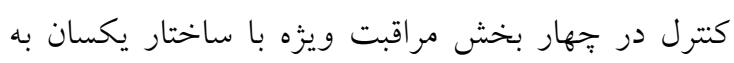

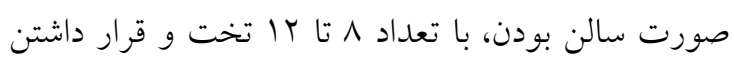
ايستخاه يرستارى در وسط بخش، از دو دانشگاه انجام

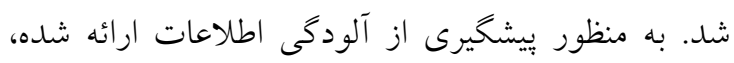
بطور تصادفى (قرعه كشى) بخشها در دو گروه مداخله

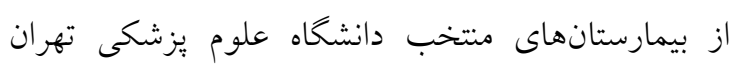

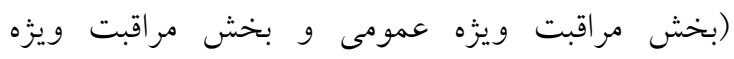

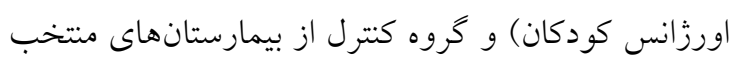

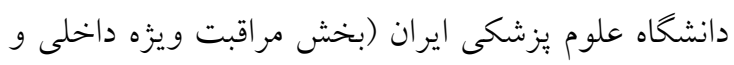

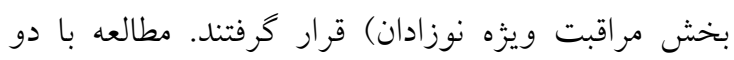

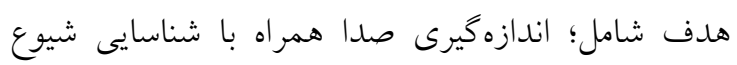

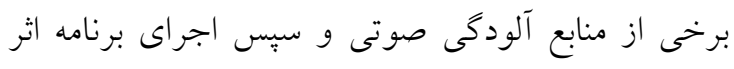

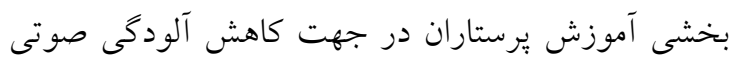

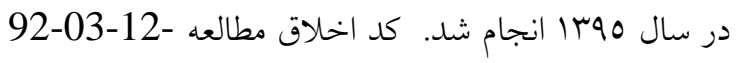
24282-102280 و كد ثبت (رجيسترى) كارآزمايى بالينى ايران: IRCT2014060717972N2 ابزار مطالعه جهت اندازهگيرى صدا، دستخاه صدا سنج

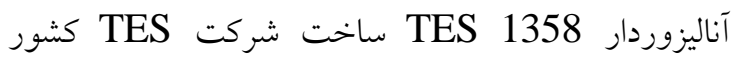
تايوان بود كه قابليت اندازهيرى تراز فشار صوتارت Cو A را در شبكه وزنى (Sound pressure level) داشت. دامنه اندازهيرى اين دستكاه از •r تا • با دسىبل وزيل بود و توسط متخصص صداسنج مطابق با دستورالعمل كارخانه سازنده و با استفاده از مقياس صداهاى استاندارد

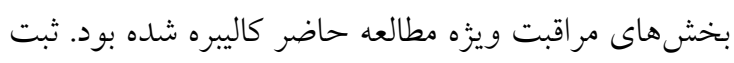

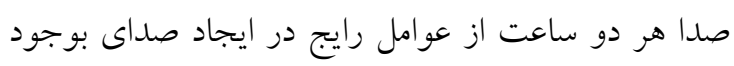

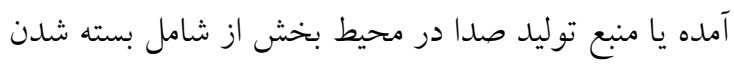

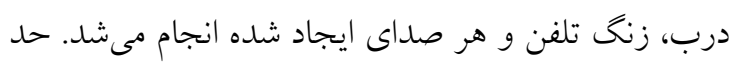
متوسط صداهاى ايجاد شده هر دو ساعت بر حسب دسى دسى رسى

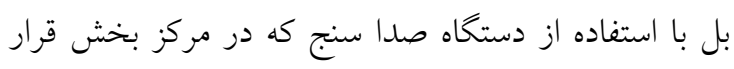

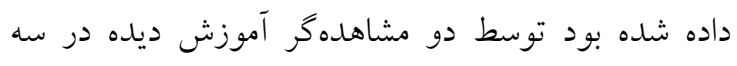

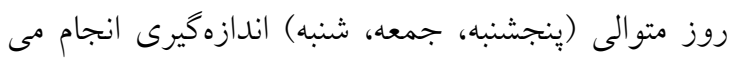


در طول مطالعه طبق معمول در هيج كدام از بخشها

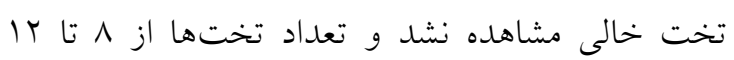
تخت متغير بود و از نظر ساختارى در آناليز دادههاى

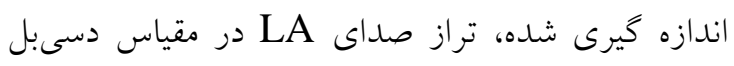

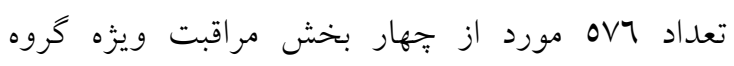

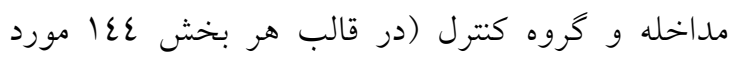

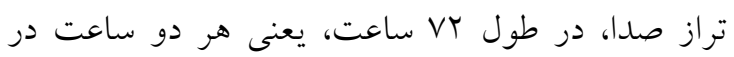

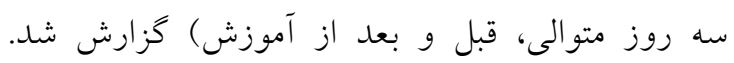
انجام آزمون كولموكروف- اسميرنوف نشان دوز داد كه دادهها

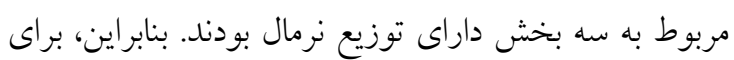

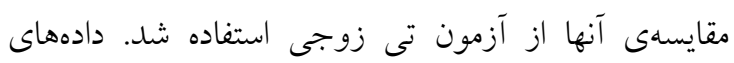

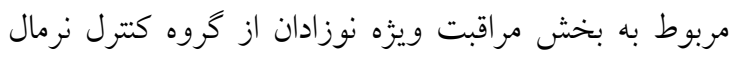
نبود كه از آزمون نايارامترى ويلكاكسون استفاده شد. در آناليز آمارى جهت برررسى اثر آموزش با مقايسه ميانكين

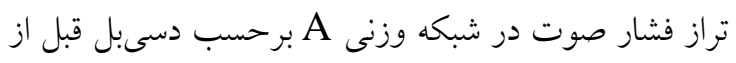

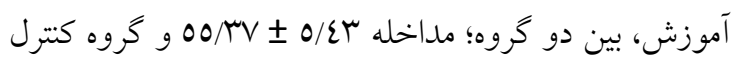
t-test براى دو گروه اختلاف

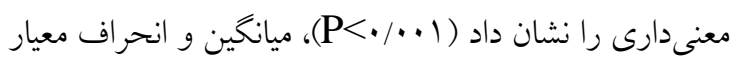

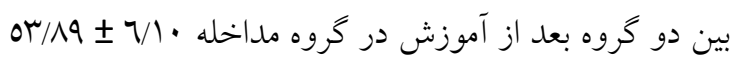
و در كروه كترل OV/V9

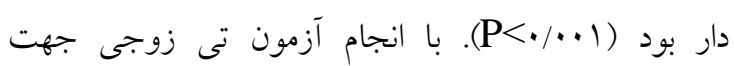

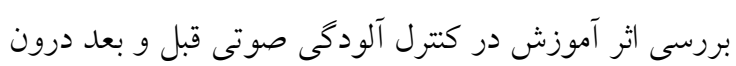

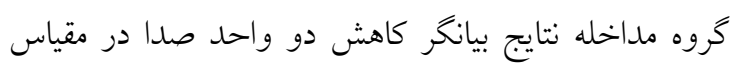

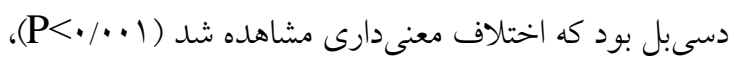
همجنين درون كروه كنترل نيز قبل و بعد از آموزش نتايج

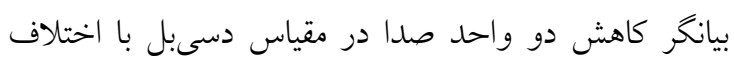

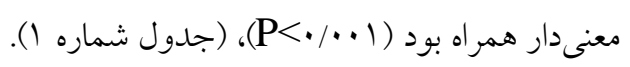

شدت صدا در بخشهاى گروه مداخله و گروه كنترل اندازه

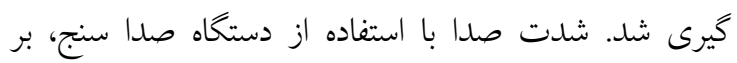

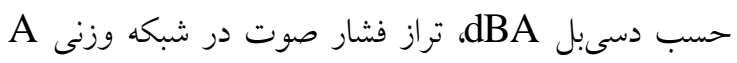

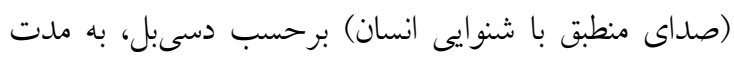

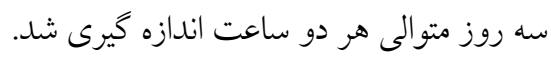
در ادامه آموزش بر اساس نظر شركت كنند مان در كاركاه،

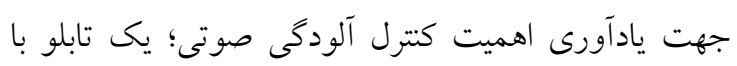

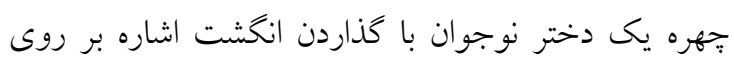
بينى خود، به عنوان هشدار براى رعايت سكوت درو در ايستّاه

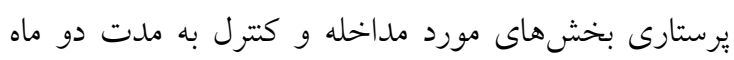

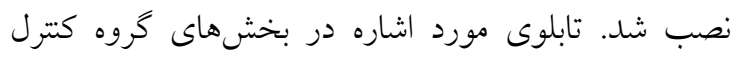

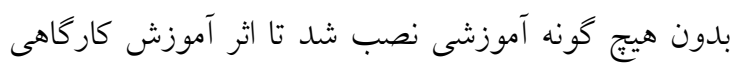

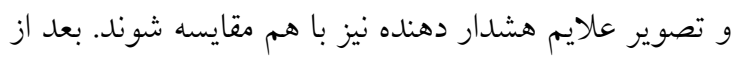

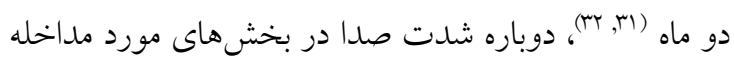

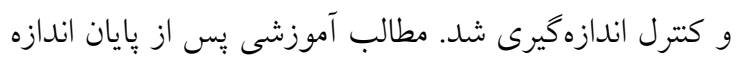

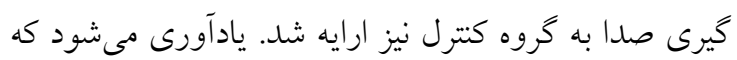

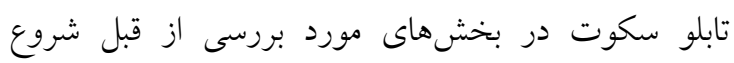
مطالعه نصب نبود. نتايج حاصل از دادههاى تراز صداى بخش هاى مودرد ماند مداخله

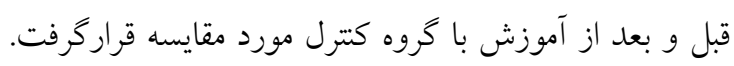

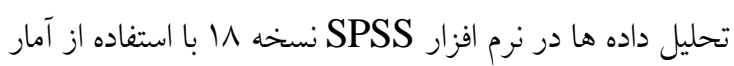

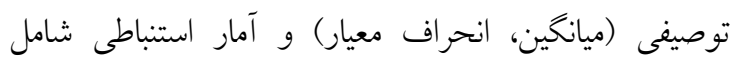

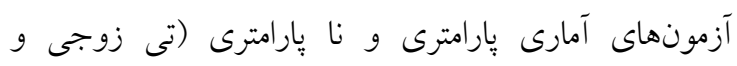
ويلكاكسون) انجام شد.

\section{يافتهها}

جدول شماره ا: مقايسه ميانكَين تراز فشار صوت در شبكه وزنى A بر حسب دسىبل در دو تروه مداخله و كنترل قبل و بعد از آموزش كنترل

\begin{tabular}{|c|c|c|c|c|}
\hline \multirow[t]{2}{*}{ P-Value } & بعد از آموزش & قبل از آموزش & \multirow[t]{2}{*}{ تعداد } & \multirow[t]{2}{*}{ كرومها } \\
\hline & ميانكين و انحراف معيار & ميانكين و انحر اف معيار & & \\
\hline$(\mathrm{P}<\bullet / \cdot \cdot 1)$ & $o r / \wedge q \pm 7 / 1$. & $00 / r V \pm 0 / \varepsilon r$ & $r M$ & مداخله \\
\hline \multirow[t]{2}{*}{$(\mathrm{P}<\bullet / . \cdot 1)$} & OV/Vq $\pm\{/ 97$ & $09 / 10 \pm 0 / 41$ & $r M$ & كنترل \\
\hline & $(\mathrm{P}<\bullet / \cdot \bullet)$ & $(\mathrm{P}<\bullet / . .1)$ & \multicolumn{2}{|c|}{ P-Value } \\
\hline
\end{tabular}


ميانخين و انحراف معيار صدا در بخش مراقبت ويزه

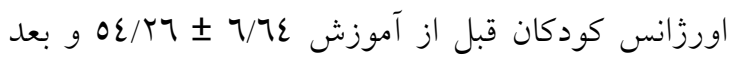
از آموزش به

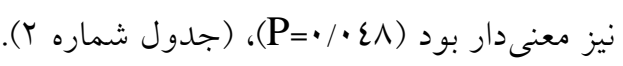

در رابطه با ميانخين و انحراف معيار صدا در بخشهاى

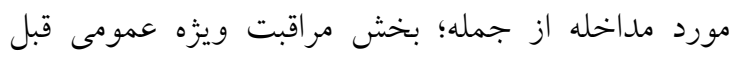

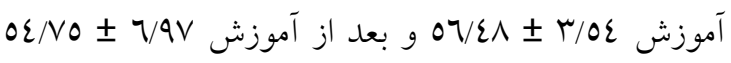

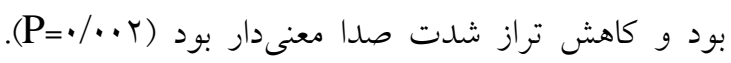

جدول شماره r: توصيف و تحليل ميانكين و انحراف معيار تراز فشار صوت در شبكه وزنى A برحسب دسىبل در بخش هاى تروه مطالعه P-Value تراز صدابرحسب دسى ميل

\begin{tabular}{|c|c|c|c|c|c|}
\hline & تعل ت ت & ميانخين و انحراف معيارترازصوت آموزش آموت & ميانخين و انحراف معيارترازصوت آموزت & & 0 \\
\hline $\mathrm{P}=\cdot / \cdots r$ & $1 \varepsilon \varepsilon$ & $0 \varepsilon / V 0 \pm V / 9 V$ & $0 \tau / \varepsilon \wedge \pm r / 0 \varepsilon$ & مر اقبت ويزٔه عمومى & $\varepsilon$ \\
\hline $\mathrm{P}=\cdot / \cdot \varepsilon \wedge$ & $1 \varepsilon \varepsilon$ & $o r / \cdot r \pm \varepsilon / \Lambda \Lambda$ & $0 \varepsilon / T\urcorner \pm \tau / 7 \varepsilon$ & مراقبت ويثه اورزانس & $\frac{\gamma}{\xi}$ \\
\hline $\mathrm{P}=\cdot / \cdots 1$ & $1 \varepsilon \varepsilon$ & $0 V / 9 T \pm 0 / \cdot 7$ & $71 / 17 \pm \varepsilon / \varepsilon r$ & مر اقبت ويزه داخلى & \\
\hline $\mathrm{P}=\cdot / 1 \wedge\rceil$ & $1 \varepsilon \varepsilon$ & $O V / \neg V \pm \varepsilon / A V$ & $O N / O Y \pm 0 / \varepsilon q$ & مراقبت ويزه نوزادان & $\xi$ \\
\hline
\end{tabular}

در مسير درب ورود و خروج بوده و معنىدار بود

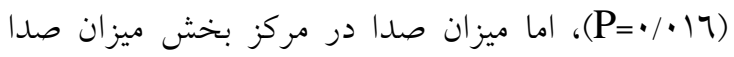

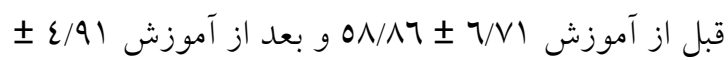

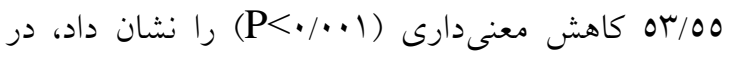
كنار بالين بيمار هم قبل از آموزش

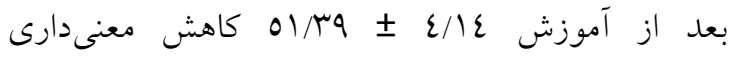

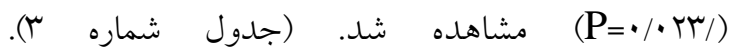

همجنين ميانخين و انحراف معيار كاهش صداى اندازه

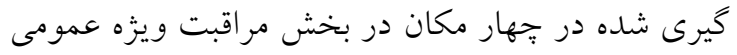
قبل از آموزش (OT/70 (O\&/rT $\pm V / T q)$ بخش مراقبت ويزه اورزانس كودكان نيز در ناحيه درب

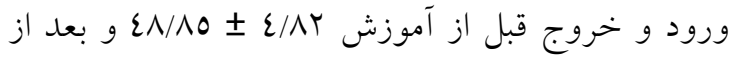

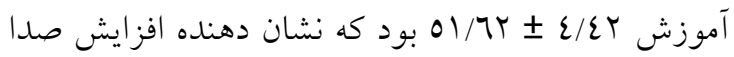

جلول شماره ب:توصيف و تحليل ميانكين و انحراف معيار تراز فشار صوت در شبكه وزنى A برحسب دسىبل در مكانهاى اندازهيرى شده در بخشهاى تروه مداخله

\begin{tabular}{|c|c|c|c|c|c|c|}
\hline \multirow{3}{*}{$\mathrm{P}$ value } & \multicolumn{2}{|c|}{ مراقبت ويزه عمومى } & \multirow{3}{*}{$\mathrm{P}$ value } & \multicolumn{2}{|c|}{ مراقبت ويزه اورزانس كودكان } & \multirow{3}{*}{ مكان و صداى نوع } \\
\hline & دو ماه بعد از آموزش & ق قبل از آموزش & & دو ماه بعد از آموزش & ق قبل از آموزش & \\
\hline & ميانخين و انحراف معيار & ميانخين و انحر اف معيار & & ميانگين و انحر اف معيار & ميانخين و انحراف معيار & \\
\hline $\mathrm{P}=\cdot / \mathrm{VTO}$ & $0 \varepsilon / 9 \varepsilon \pm 7 / 11$ & $\Delta \varepsilon / 7 r \pm r / q$. & $\mathrm{P}=. / \cdot 17$ & $01 / 7 r \pm \varepsilon / \varepsilon r$ & $\varepsilon \wedge / \wedge O \pm \varepsilon / \wedge r$ & دربورود و خروج \\
\hline $\mathrm{P}=\cdot / \cdot 0 \varepsilon$ & $00 / 0 \cdot \pm 7 / 97$ & $0 V / 09 \pm r / 0$. & $\mathrm{P}=\cdot / \mathrm{V} 91$ & $00 / 0 r \pm \varepsilon / 97$ & $00 / Y T \pm 0 / \pi$ & محوطهايستگاهيرستارى \\
\hline $\mathrm{P}=\cdot / \cdot \varepsilon V$ & $0 \varepsilon / r า \pm V / \neg \varepsilon$ & $07 / v 7 \pm r / \varepsilon q$ & $\mathrm{P}<\bullet / \cdots 1$ & $0 r / 00 \pm \varepsilon / 91$ & $0 \wedge / 17 \pm 7 / V 1$ & مركز بخش \\
\hline $\mathrm{P}=. / \cdot r 7$ & $O \varepsilon / T r \pm V / T q$ & $07 / 9 \varepsilon \pm r / 70$ & $\mathrm{P}=. / \cdot r \mu$ & $01 / \pi q \pm \varepsilon / 1 \varepsilon$ & Or/11 $\pm 0 / 0 r$ & در كنار بالين بيمار \\
\hline
\end{tabular}

جمعه و شنبه)، در جهار مكان بخشها نشان داد: روز ينج

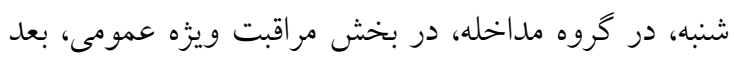

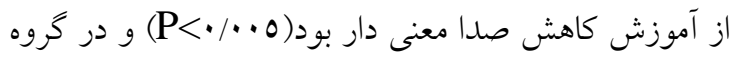
كتترل، كاهش صدا در بخش مراقبت ويزه نوزادان معنى دار

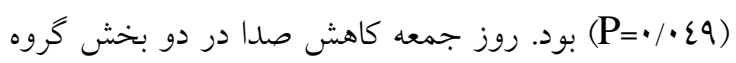

ميزان صدا در بخشهاى كروه كنترل در مرحله قبل و بعد از آموزش به نسبت بخشهاى مورد مداخله بالاتر بود (جدول

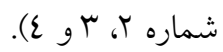
تحليل آمارى تراز صدا بر اساس روزها (هر روز با خودش)

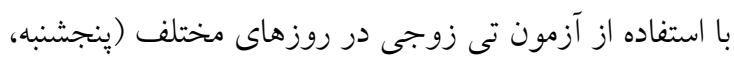




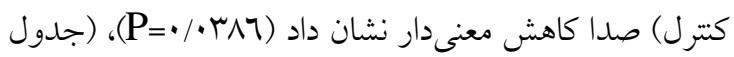
كنترل معنى دار بود. روز شنبه بين جهار بخش كروه مداخله

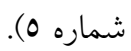

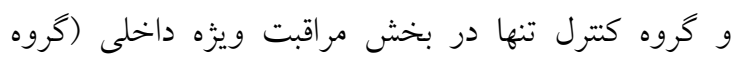

جدول شماره 乏: توصيف و تحليل مقايسه ميانكين و انحراف معيار تراز فشار صوت در شبكه وزنى A بر حسب دسىبل در بخشهاى ترووه كترل

\begin{tabular}{|c|c|c|c|c|c|c|}
\hline \multirow{3}{*}{$P$ value } & \multicolumn{2}{|c|}{ بخش مراقبت ويثُه نوزادان } & \multirow{3}{*}{$P$ value } & \multicolumn{2}{|c|}{ مر اقبت ويزٔه داخلى } & \multirow{2}{*}{ مكان و صداى } \\
\hline & دو ماه بعد از آموزش & قبل از آموزش & & دو ماه بعد از آموزش & قبل از آموزش & \\
\hline & ميانكين و انحراف & ميانكين و انحراف & & ميانكين و انحراف & ميانكين و انحراف & نوع LA \\
\hline
\end{tabular}

\begin{tabular}{|c|c|c|c|c|c|c|}
\hline & معيار & معيار & & معيار & معيار & \\
\hline $\mathrm{P}=\pi$ ror & $0 T / 9 T \pm 0 / \varepsilon \wedge$ & $01 / V 9 \pm 0 / 01$ & $\mathrm{P}=. T \Lambda T$ & $\Delta V / r \cdot \pm 0 / 0 r$ & $O N / O r \pm r / N 1$ & درب ورود و خروج \\
\hline $\mathrm{P}=\cdot / / 7 \pi$ & $O V / T q \pm \varepsilon / 1 q$ & $\Delta N / N \mid \pm 0 / 7 \varepsilon$ & $\mathrm{P}<\cdot / \cdot \cdot 1$ & $O V / T I \pm \varepsilon / r$. & $T r / I V \pm \varepsilon / 09$ & محوطهايستاماير ستارى \\
\hline $\mathrm{P}=\cdot / \cdot r \varepsilon$ & $07 / \varepsilon \varepsilon \pm \varepsilon / 10$ & ON/Or $\pm \varepsilon / I r$ & $\mathrm{P}<\bullet / \cdot \cdot 1$ & $70 / 7 T \pm \varepsilon / \varepsilon \varepsilon$ & $7 r / .9 \pm r / 99$ & مركز بخش \\
\hline $\mathrm{P}=\cdot / \cdot 1 \mathrm{VO}$ & $\neg \cdot / \cdot r \pm\{/ q 1$ & $O N / \cdot Y \pm T / 7 T$ & $\mathrm{P}=\cdot / r q 1$ & $\tau \cdot / T \varepsilon \pm 0 / \cdot r$ & $T / \Lambda \varepsilon \pm \varepsilon / \pi \mu$ & در كنار بالين بيمار \\
\hline
\end{tabular}

جلول شماره م: توصيف و تحليل مقايسه ميانكَين و انحراف معيار تراز فشار صوت در شبكه وزنى A برحسب دسىبل در مكانهاى مختلف در بخشهاى تروه مداخله و كتترل

\begin{tabular}{|c|c|c|c|c|c|c|c|c|c|}
\hline \multicolumn{3}{|c|}{ روز سوم شنبه } & \multicolumn{3}{|c|}{ روز دوم جمعه } & \multicolumn{3}{|c|}{ روز اول بنجشنبه } & \\
\hline \multicolumn{3}{|c|}{ تراز صداى LA } & \multicolumn{3}{|c|}{ تراز صداى LA } & \multicolumn{3}{|c|}{ تراز صداى LA } & \\
\hline \multirow{2}{*}{ P Value } & دو ماه بعد & قبل از آموزش & \multirow[b]{2}{*}{$\begin{array}{c}\mathrm{P} \\
\text { Value }\end{array}$} & دو ماه بعد & قبل ازآموزش & \multirow[b]{2}{*}{ P Value } & دو ماه بعد & قبل ازآموزش & \\
\hline & ميانگين و معيار & ميانخين & & ميانخين & ميانخين & & ميانخين م و & ميانخين $\quad$ و معيار & بخش \\
\hline $\mathrm{P}=\cdot / \cdot \wedge$ & $00 / 7 \varepsilon \pm 7 / 9 T$ & $O V / \varepsilon q \pm r / \varepsilon \varepsilon$ &.$/ 70 \mathrm{~V}$ & $0 V / \varepsilon Y \pm V / V \varepsilon$ & $\Delta \tau \cdot \eta \pm r / M r$ & $\mathrm{P}<\cdot / \cdot \cdot 1$ & $O Y / Y I \pm V / O Y$ & $00 / \Lambda \Lambda \pm r / A V$ & مراقبت عيزه \\
\hline $\mathrm{P}<\cdot / \neg \varepsilon r$ & Or/NI $\pm \sum \pi r$ & $0 r / r 7 \pm 0 / 1 r$ & 每 & $0 \varepsilon / 0 . \pm 0 / \cdot r$ & $00 / 7 V \pm V / a r$ & $\mathrm{P}=\cdot / \cdot \pi r$ & $01 / V 7 \pm \varepsilon / 97$ & $\Delta r / \wedge 7 \pm 7 / 2 V$ & اورثانس كورديتهان \\
\hline $\mathrm{P}=\cdot / \cdot r \wedge\urcorner$ & $7 \cdot / \cdot \wedge \pm \varepsilon / 0$ & $\Delta 9 / r \Lambda \pm r / 91$ & $\cdot / \cdot r$ & $07 / 70 \pm \varepsilon / 10$ & $7 r / r u \pm \varepsilon / 1 r$ &.$/ \cdot T V T$ & $O V / \cdot\{ \pm 0 / r)$ & $71 / \wedge \varepsilon \pm \varepsilon / 77$ & مراقبتويزثداخلى \\
\hline $\mathrm{P}=\cdot /$ IV & $7 \cdot / \cdot \Lambda \pm \varepsilon / 0$. & $\Delta \tau / \backslash \Lambda \pm r / \Sigma\rceil$ & $\because \cdot r r$ & $07 / T V \pm \varepsilon / \Lambda 1$ & $O N / A T \pm V / T \Lambda$ & $\cdot 1 \cdot \varepsilon 9$ & $07 / / 0 \pm \varepsilon / \varepsilon \varepsilon$ & $7 \cdot / 0 \cdot \pm \varepsilon / 1 r$ & بخش ميزه نوزادبت \\
\hline
\end{tabular}

\section{بحث و نتيجه كيرى}

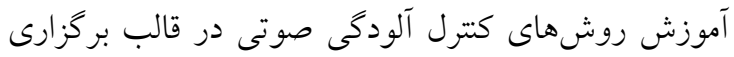
كارگاه آموزش روشهاى كنترل آلودگى صوتى جهت ارتقاء

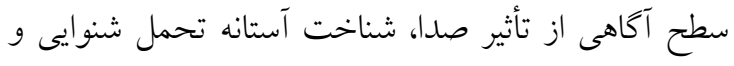

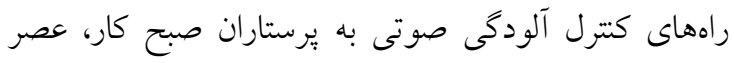

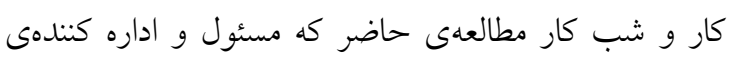

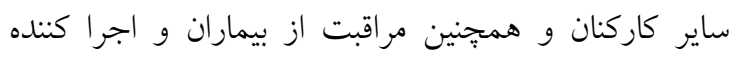

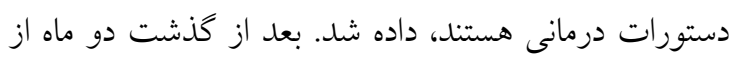

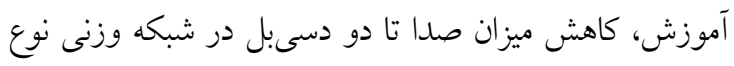
A
از عوامل توليد صدا در بخشهاى مورد مداخله و كترل به طور يكسان صداى مكالمه كاركنان بخصوص در ايستاه يرستارى، صداى زنخ تلفن، صداى كفش كاركنان، صداى

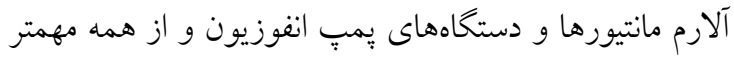
بذيرش بيمار به ويزه بذيرش فورى بيماران از بيشترين علل

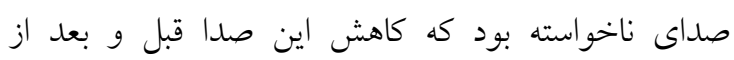

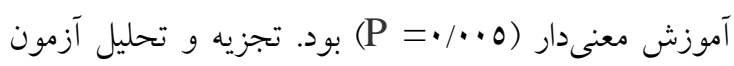

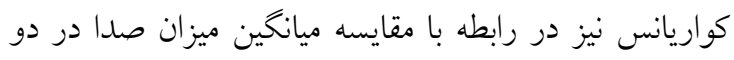
كروه كتترل و مداخله اختلاف معنادارى را نشان نداد. 
انجام آموزش مداوم كاركنان و نصب تابلوى هشدار اندازه

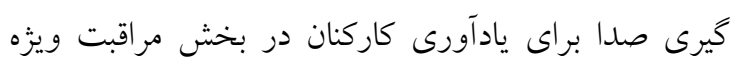

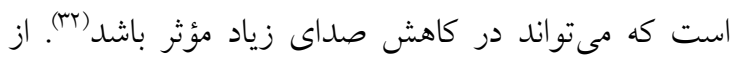
طرف ديخر يزوهشكران در بررسى سطح آكاهى برستاران

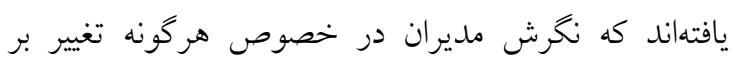

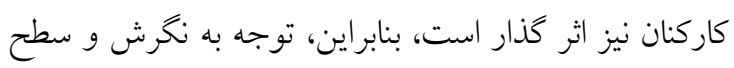

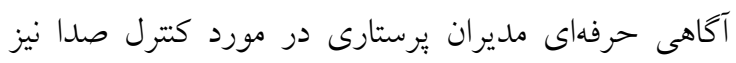

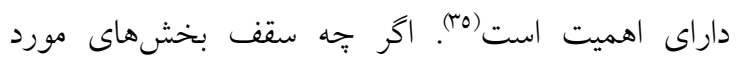

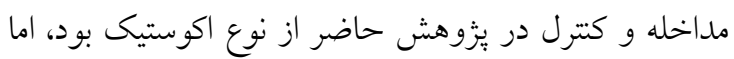

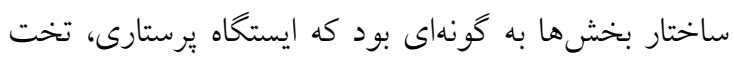

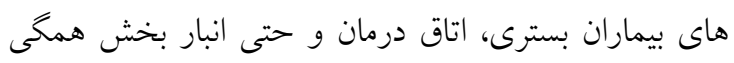

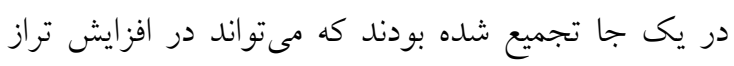
فشار صوت اثر كذار باشد. عدم تغيير صدا در ايستخاه

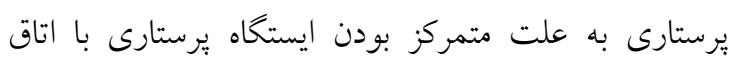

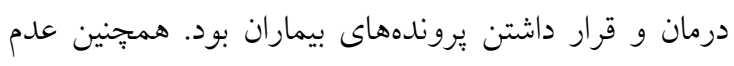
تغيير صدا در محدوده درب ورود و خروج هم به دليل نبود

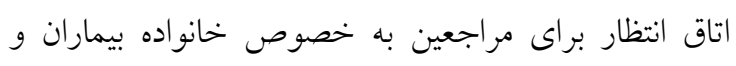

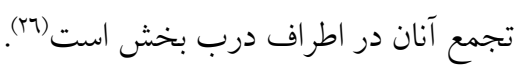

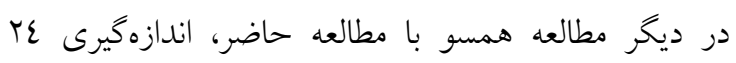

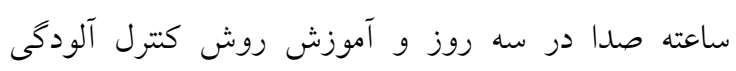

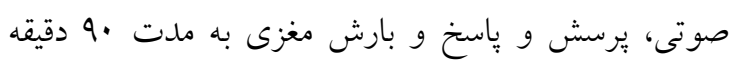

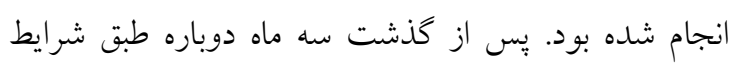

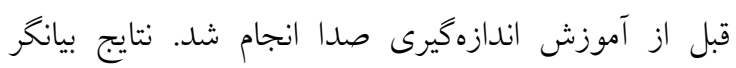

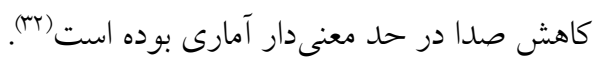

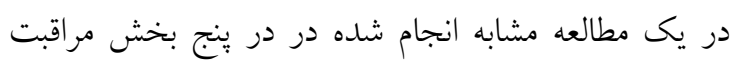

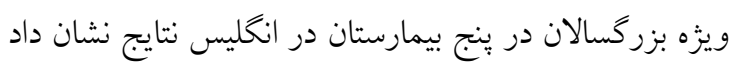

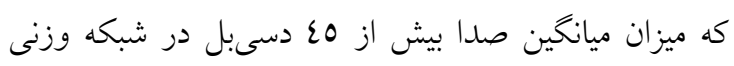

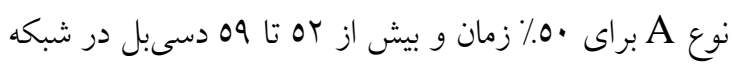

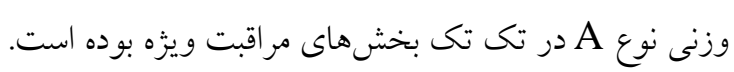

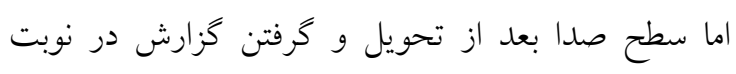
كارى شب، روبه كاهش و تا ساعت جهار صبح كاهش صدا

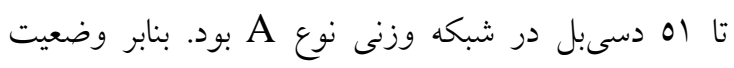

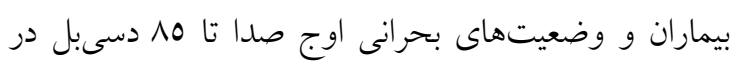
تمام قسمتهاى بخش حتى تا 17 نوبت در هر ساعت در ور
سطح ميزان توصيه سازمان بهداشت جهانى در روز تا

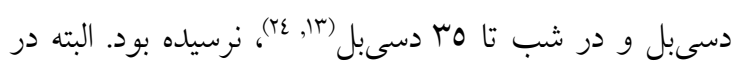
مقايسه تأثير آموزش در گروه مداخله و كروه كترل، در آناليز

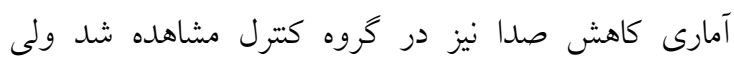

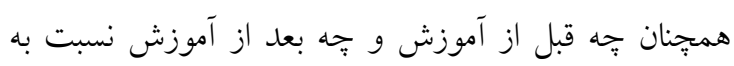

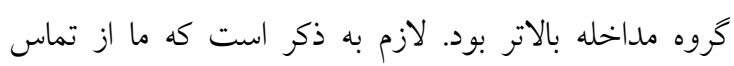

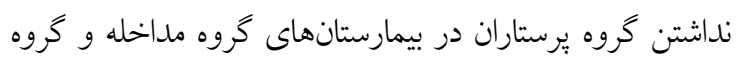

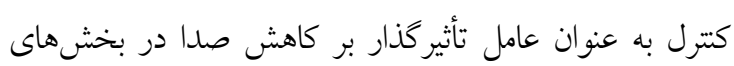

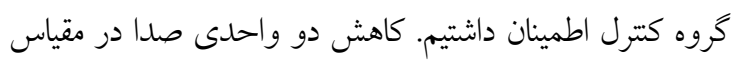

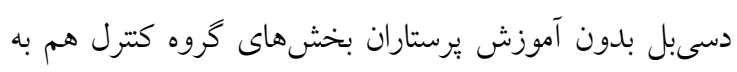

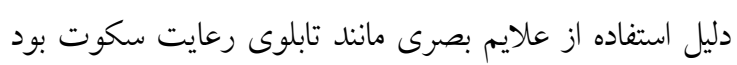

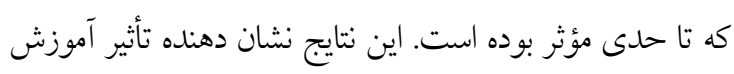

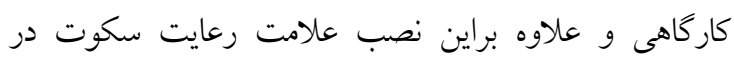

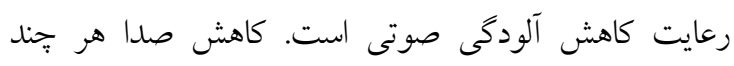

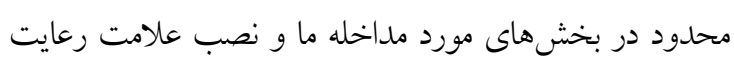

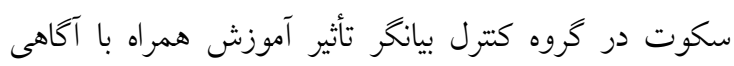
يرستاران و اجراى اصول كاهش آلودخى صوتى و از همه مهمتر درى بهبود شرايط محيط كارى بوده است. ولى بالاتر بودن تراز

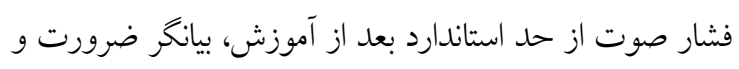

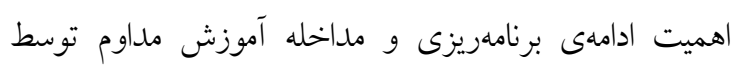

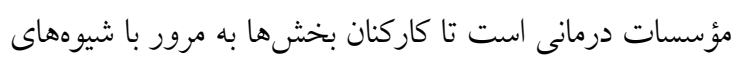

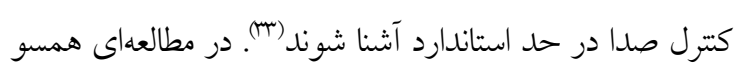

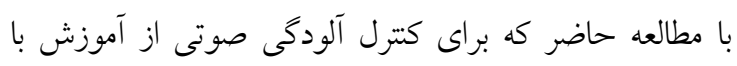

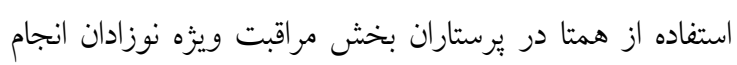

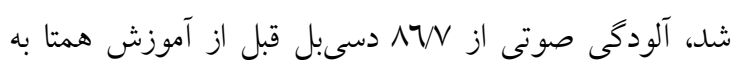

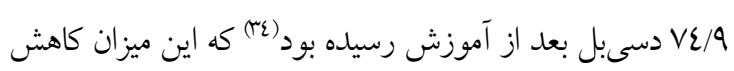

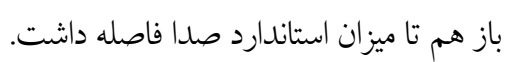

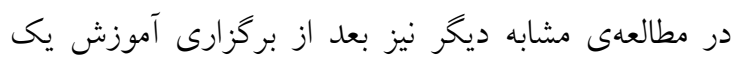

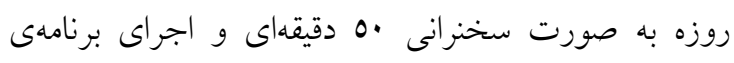
آموزشى روشهاى كاهش صدا براى كاركنان بخش مراقبت

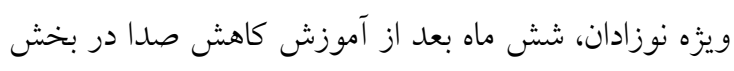

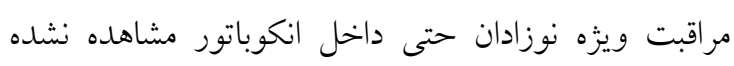

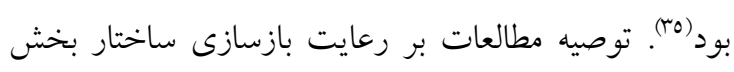

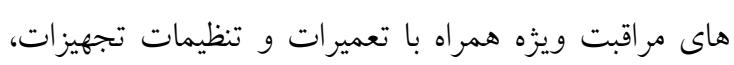


آموزشى اختصاصى براى هر بخش متناسب با نوع خدمت

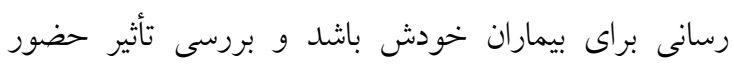

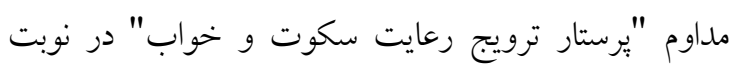
كارى صبح، عصر و شب با گروه مداخله و گروه كتترل سنجيده شود و بررسى تأثير صدا بر خود بزشكان و برستاران در بخشهاى مختلف نيز ضرورى است. علاوه بر اين در آينده همكارى يزوهشى بين كاركنان واحدهاى بيمارستانى و

$$
\text { متخصصين گروه اكوستيك نيز بايد فراهم شود. }
$$

نتايج مطالعه حاضر نشان داد كه استفاده از يك روش ساده آموزش مداوم در دورههاى تنظيم شده به كاركنان به خصوص برستاران و كترل صداى وسايل بخش ها، همراه با استفاده از علايم بصرى مانند علامت سكوت آلودكى صوتى را كاهش مىدهد. در كنار اقدامات فوق رعايت نظارت با حضور "يرستار ترويج رعايت سكوت و خواب" در تمام نوبتهاى كارى در كنترل آلودگى صوتى كمك كننده خواهد بود.

تعارض منافع: مطالعه حاضر هيج تعارض منافع ندارد

\section{تقلدير و تشكر}

بلدين وسيله از معاونت يزّوهشى دانشگاه علوم يزشكى ايران و دانشكده بِرستارى ايران و همجنين از مديريت يرستارى و مديريت بيمارستانهاى دانشخاه علوم يزشكى تهران و دانشخاه علوم يزشكى ايران در راستاى كمك و همكارى مؤثر براى انجام مطالعه حاضر تشكر مىنماييم.
شب و با تعداد بيشتر در روز اتفاق ميافتاده است. اندازه صدا طبق دستورالعمل سازمان بهداشت جهانى وقتى بود كه تمام تجهيزات و وسايل خاموش مىشدند (MT). همجنين در مرور مطالعات در رابطه با رعايت صداى استاندارد در بخشها، ما به مطالعهاى كه رعايت صدا در حد توصيه سازمان بهداشت جهانى در بخشهاى بيماران بسترى

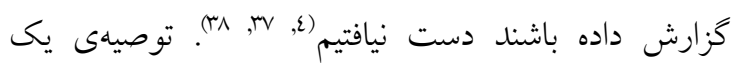
مطالعه بعد از شش ماه آموزش مداوم رعايت و كتترل آلودگى صوتى با عدم كاهش صدا در بخش مراقبت ويزه نوزادان و همينطور داخل انكوباتور اين است كه علاوه بر اهميت دادن به برنامههاى آموزشى و تداوم نظارت، براى تغيير نخرش گروه مراقبت كننده در بخشهاى مراقبت ويزه؛ تأكيد بر تكرار مدام اندازهيرى صدا با دستگاه صداسنج در هر زمانى است تا اين كه به مرور كاركنان به اهميت كترل صدا آكاه شوند (ro). تأثير انجام مراقبت و اجراى تدابير درمانى - مراقبتى بيمار دجّار بحران بر ساير بيماران به عنوان عوامل مخدوشخر در مطالعه حاضر قابل كنترل نبود. اما از آنجايى كه تا زمان مطالعه حاضر رعايت سكوت به عنوان يك مراقبت استاندارد شده در بخشهاى تحت مطالعه ما مورد توجه نبود، همجنين به دليل سالن بودن بخشها در مطالعه حاضر و تيديدار شدن موقعيتهاى بحرانزا در زمان يذيرش يا بد حال شدن ناكهانى بيمارى دلايل آشكار عدم

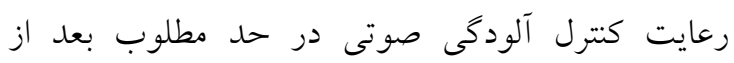
آموزش بود. از طرف ديخر ما محدوديت مداخله در رعايت سكوت را داشتيم. براى تداوم رعايت سكوت در واحدهاى درمانى، بيشنهاد مطالعهى حاضر اين است كه در مطالعات آينده تنظيم برنامه

\section{References}

1. Aslam MJ, Aslam MA, Batool A. Effect of noise pollution on hearing of public transport drivers in Lahore city. Pakistan Journal of Medical Sciences. 2008;24(1):142.

2. World Health Organization, World Health Organization. Ageing, Life Course Unit. WHO global report on falls prevention in older age. World Health Organization; 2008.

3. Stafford A, Haverland A, Bridges E. Noise in the ICU. AJN The American Journal of Nursing. 2014 1;114(5):57-63. 
4. Xie H, Kang J, Mills GH. Clinical review: The impact of noise on patients' sleep and the effectiveness of noise reduction strategies in intensive care units. Critical Care. 2009 Apr;13(2):20815.

5. Zhang M, Kang J. Towards the evaluation, description, and creation of soundscapes in urban open spaces. Environ Plann B: Plann des. 2007;34(1):68-86.

6. Jones C, Dawson D. Eye masks and earplugs improve patient's perception of sleep. Nursing in critical care. 2012;17(5):247-54.

7. Demoule A, Carreira S, Lavault S, Pallanca O, Morawiec E, Mayaux J, Arnulf I, Similowski T. Impact of earplugs and eye mask on sleep in critically ill patients: a prospective randomized study. Critical Care. 2017;21(1):284-93.

8. Asgharnia HA, Tirgar A, Amouei A, Fallah SH, Khafri S, Mohammadi AA, Peykarporsan F, Rahimi D, Beykaei SB, Shirkhani Z. Noise pollution in the teaching hospitals of Babol (Iran) in 2012. Journal of Babol University of Medical Sciences. 2014 15;16(4):64-9. [Persian]

9. Falk SA, Woods NF. Hospital noise- levels and potential health hazards. New England Journal of Medicine. 1973 11;289(15):774-81.

10. B Busch-Vishniac IJ, West JE, Barnhill C, Hunter T, Orellana D, Chivukula R. Noise levels in Johns Hopkins hospital. J Acoust Soc Am. 2005;118(6):3629-45.

11. Meyer TJ, Eveloff SE, Bauer MS, Schwartz WA, Hill NS, Millman RP. Adverse environmental conditions in the respiratory and medical ICU settings. Chest. 1994 1;105(4):1211-6.

12. Konkani A, Oakley B, Penprase B. Reducing hospital ICU noise: a behavior-based approach. $J$ Healthc Eng. 2014;5(2):229-46.

13. Zamani K, Asgharnia HA, Yazdani J, Taraghi Z. The effect of staff training on the amount of sound pollution in the intensive care unit. Journal of Nursing and Midwifery Sciences. 2018;5(4):130-3. [Persian]

14. Mello BC, Gagnon MR, Hanna TS, Pinette WJ. Increasing the Quality of Patient Care by Reducing Noise Levels in the Healing Environment. 2013.

15. Kang J. Urban sound environment. CRC Press; 2006 Sep 13.

16. Helton MC, Gordon SH, Nunnery SL. The correlation between sleep deprivation and the intensive care unit syndrome. Heart lung. 1980;9(3):464-8.

17. McGuire BE, Basten CJ, Ryan CJ, Gallagher J. Intensive care unit syndrome: a dangerous misnomer. Arch Intern Med. 2000;160(7):906-9.

18. Cmiel CA, Karr DM, Gasser DM, Oliphant LM, Neveau AJ. Noise Control: A Nursing Team's Approach to Sleep Promotion: Respecting the silence creates a healthier environment for your patients. AJN. 2004;104(2):40-8.

19. Walder B, Francioli D, Meyer JJ, Lançon M, Romand JA. Effects of guidelines implementation in a surgical intensive care unit to control nighttime light and noise levels. Critical care medicine. 2000;28(7):2242-7.

20. Zamberlan-Amorim NE, Fujinaga CI, Hass VJ, Fonseca LM, Fortuna CM, Scochi CG. Impact of a participatory program to reduce noise in a Neonatal Unit. Rev lat Am Enfermagem. 2012;20(1):10916.

21. Li Li SY, Wang TJ, Vivienne Wu SF, Liang SY, Tung HH. Efficacy of controlling night-time noise and activities to improve patients' sleep quality in a surgical intensive care unit. J Clin Nurs. 2011;20(3-4):396-407.

22. Berglund B, Lindvall T, Schwela DH, World Health Organization. Guidelines for community noise. 1999.

23. Johansson L, Knutsson S, Bergbom I, Lindahl B. Noise in the ICU patient room-Staff knowledge and clinical improvements. Intensive Crit Care Nurs. 2016 ;1;(35):1-9.

24. Committee on Environmental Health. Noise: a hazard for the fetus and newborn. Pediatrics. 1997;100(4):724-7.

25. Costa GD, de Lacerd AB, Marques J. Noise on The Hospital Setting: Impact on Nursing Professionals'health. Revista CEFAC. 2013 o;15(3):642-52.

26. Kooshanfar Z, T Mohammadi K, Paryad E, Kazemnezhad E, Golhosseini SJ. Noise Pollution Level in Rasht Hospital's Intensive Care Units. Journal of Guilan University of Medical Sciences. 2016 15;25(99):10-6. [Persian] 
27. Moore MM, Nguyen D, Nolan SP, Robinson SP, Ryals B, Imbrie JZ, Spotnitz W. Interventions to reduce decibel levels on patient care units. American Surgeon. 1998;64(9):894-9.

28. Karimi R, Khajeh M, Arezumaniyans S, Mehran A, Heidarzadeh M. The Effect of Noise Modifying in Nicu on Premature Infants'behavioral Responses. Knowledge and Health. 2014;9 (3): 45-53. [Persian]

29. Brandon D, Ryan D, Barnes A. Effect of environmental changes on noise in the NICU. Neonatal Network. 2007;26(4):213-8.

30. ISO I. 9612: Acoustics-Determination of Occupational Noise Exposure-Engineering Method. Geneva, Switzerland: International Organization for Standardization. 2009.

31. Elander G, Hellström G. Reduction of noise levels in intensive care units for infants: evaluation of an intervention program. Heart \& Lung: The Journal of Acute and Critical Care. 1995;24(5):376-9.

32. Calikusu Incekar M, Balci S. The effect of training on noise reduction in neonatal intensive care units. J Spec Pediat Nurs. 2017;22(3):e12181-9.

33. Yurdakul M, Beşen MA, Erdoğan S. The organisational silence of midwives and nurses: reasons and results. Journal of nursing management. 2016;24(5):686-94.

34. Biabanakigoortani A, Namnabati M, Abdeyazdan Z, Badii Z. Effect of peer education on the noise management in Iranian neonatal intensive care unit. Iranian journal of nursing and midwifery research. 2016;21(3):317-21. [Persian]

35. Tsunemi MH, Kakehashi TY, Pinheiro EM. Noise at the neonatal intensive care unit after the implementation of an educational program. Texto \& Contexto-Enfermagem. 2012;21(4):775-82.

36. Darbyshire JL, Young JD. An investigation of sound levels on intensive care units with reference to the WHO guidelines. Critical Care. 2013;17(5):R187-95.

37. Christensen M. Noise levels in a general surgical ward: a descriptive study. Journal of clinical nursing. 2005;14(2):156-64.

38. Tainter CR, Levine AR, Quraishi SA, Butterly AD, Stahl DL, Eikermann M, Kaafarani HM, Lee J. Noise levels in surgical ICUs are consistently above recommended standards. Critical care medicine. 2016;44(1):147-52. 